\title{
Presentación. Posverdad en las redes
} Presentation: Post-truth on the Networks

\author{
Lucía Ballesteros-Aguayo \\ Universidad de Sevilla \\ lballesteros@us.es \\ Juan-Antonio Nicolás \\ Universidad de Granada \\ jnicolas@ugr.es
}

No cabe duda de que uno de los problemas que han visto la luz en este comienzo del siglo xxi ha sido el del manejo de la información a través del tejido social. El ideal de máximo acceso a la información y al saber ha dado un salto cualitativo con el desarrollo espectacular de las tecnologías de la información. Estas han tenido un efecto multiplicador en la generación y difusión de información similar (o tal vez mayor) al que tuvo la imprenta como impresión de tipos móviles en el siglo xv. Internet ha sido la gran ventana al saber para la mayoría de la humanidad, que fue el sueño de muchos intelectuales y científicos durante siglos. En cuanto realización del interés humano por la difusión y acceso a la cultura, internet ha sido una de las instituciones que ha contribuido de manera más significativa al progreso de la humanidad. Si la imprenta de tipos móviles puso en marcha todo un Renacimiento cultural que acabó forjando la Modernidad, cabe esperar que todo lo que supone internet sea capaz también de hacer 
renacer y recrear toda la cultura moderna hoy en cuestión por no haber alcanzado el objetivo que se propuso. Este objetivo fue formulado por F. Bacon en el siglo XVI en términos de que la razón sería la instancia capaz de resolver las necesidades de la humanidad y cumplimentar sus intereses. La tradición crítico-racionalista desplegada como cultura moderna-ilustrada ha desarrollado un modelo de razón preponderante que culmina, por ahora, en ese «aparato» prodigiosamente potente que es internet.

Pues bien, las mismas ambigüedades que reflejan los balances de la Modernidad elaborados en las últimas décadas pueden encontrarse también en el «efecto internet». Esta plataforma ha generado y masificado multitud de instancias de comunicación, de producción y de difusión de información, de mecanismos de contrastación y de creación de conocimientos, hasta modificar el valor y sentido del tiempo y del espacio. Por esta vía, buena parte de los seres humanos están participando en esta gran «conversación de la humanidad, y gracias a ello se va constituyendo poco a poco la conciencia de mundo interconectado. Es lo que se ha venido llamando como «globalización».

Como cabría esperar, esta maravillosa posibilidad que el ser humano ha creado no solo ha traído progreso teórico y moral, sino que ha planteado también problemas inexistentes antes de su aparición. Muchos de ellos están ligados al control del proceso de producción de la información, la libre circulación de la misma, la fiabilidad de la información introducida en la red, la capacidad de generar noticias, la responsabilidad ante las mismas, las posibilidades de asumir y procesar los datos al alcance, la capacidad de valoración y crítica de los datos recibidos, la disponibilidad de tiempo para interactuar con la información sobrevenida, la capacidad de selección de lo noticiable frente a lo opinativo o sensacionalista disponible, etc. 
Todos estos problemas afectan la mayor parte de los miembros de las sociedades desarrolladas y tienen consecuencias en la mayoría de las disciplinas del saber. Así pues, hay problemas relacionados con los flujos de información en la red que afectan a psicología, a la economía o la filosofía (por ejemplo, el valor de la verdad); otros relacionados con el desarrollo tecnológico, ligados, por ejemplo, a la inteligencia artificial; otros problemas están vinculados a la reconstrucción e interpretación de la historia o a la formulación de los procesos educativos; en otros casos se plantean cuestiones como el modo de entender el derecho a la verdad, sea en el terreno, sea en el ámbito político, etc.

Gran parte de estos nuevos problemas están estrechamente relacionados con el mundo de la comunicación. Se trata de un ámbito complejo donde desarrollan su labor quienes se dedican profesionalmente a manejar la información en sus múltiples formatos públicos y privados. En este caso la relación con la información y su circulación es el tema explícito de discusión y ejecución. Por ello se trata de un colectivo y de un ámbito del saber y de la acción que está en la primera línea de fuego en todas estas problemáticas mencionadas. Son los primeros vigilantes y responsables de la fiabilidad de la información y de su correcta distribución, al menos en cuanto a servicio público se refiere. De ahí que entre las diversas éticas profesionales, la deontología periodística ocupe aquí el primer lugar.

Un fenómeno de carácter general y complejo ligado al desarrollo de las tecnologías de la información es la llamada «posverdad». Frente al reto que esta representa, la reconstrucción de una esfera comunicativa donde impere la ética deontológica, la contrastación de las fuentes personales expertas, la divulgación científica y la veracidad de informaciones y hechos entre otros 
elementos, constituyen no solo una necesidad urgente, sino que además representan la mejor salvaguarda para la libertad y la democracia.

De manera que la labor del comunicador como testigo fundamental del acontecer social e histórico se ve amenazada o degradada por la actitud que representa la posverdad. Ello entronca con la tarea del filósofo quien, desde Herodoto a Žižek o desde Sócrates a Byung-Chul, aborda también la búsqueda de la verdad - hoy día con múltiples facilidades y dificultades que aporta la esfera digital —. Nos encontramos, pues, con un importante cambio operado en las herramientas discursivas y en las fuentes de especialistas en las que la digitalización de la información junto con la difusión masiva, veloz y no siempre contrastada, inciden poderosamente en la generación actual en la que conviven nativos digitales con otros que no lo son.

Precisamente uno de los problemas distorsionadores o degradantes de la función periodística fundamental es la irrupción de numerosos e influyentes comunicadores ocasionales a través de las RR. SS., lo que ocasiona la necesidad de una reflexión profunda de los procesos comunicativos, intoxicados de una infopolución en cierta medida acrítica que genera desconfianza y falta de consenso tanto en la función y veracidad de los flujos comunicativos, como en la cosmovisión que se deriva. Por tanto, se impone como urgente necesidad no solo una alfabetización digital, sino también una cultura de la información.

En suma, se trata de recoger una evolución constructiva en torno a los cambios operados en los procesos cognitivos, conductuales y procedimentales a partir de la revolución que supone la irrupción de la tecnología con el consecuente cambio de paradigma en los flujos comunicativos que a su vez se vierten en distintas transformaciones en las concepciones filosóficas no 
exentas de la responsabilidad que su influencia pueda ejercer en los cambios urbanos, sociales, políticos e institucionales en nuestras sociedades actuales.

No escapa a nuestra consideración el reconocimiento del carácter móvil, complejo o poliédrico del ser humano, lo que implica aceptarlo desde una concepción procesual y multiforme en la que las revisiones de las conclusiones siempre tengan cabida desde múltiples horizontes de sentido. Ello justifica la fecundidad del carácter interdisciplinar de nuestra propuesta y el alcance de nuestras conclusiones para investigaciones futuras.

En conclusión, la tipología y las características de la muestra de ponencias que recoge este volumen constituyen un lugar en el que los resultados de la investigación permitirán reformular amplias zonas del saber. Se presentan en este volumen, por tanto, una selección de trabajos que afectan a algunas de las múltiples problemáticas puntuales que surgen en el contexto de los retos que la actitud posverdadera plantea al mundo de la comunicación. Así, hay textos que reflexionan sobre la noción misma de verdad presente en este contexto posverdadero (L. Ballesteros, C. Aguayo) y sus perversiones políticas (M. Bermúdez), otros tienen como objeto las consecuencias jurídicas (J. M. Faramiñán) o éticas y estética (E. Borges Junior) de este fenómeno; mientras que otros afrontan el desafío desde una perspectiva histórica (A. Carvajal), hermenéutica (L. Ballesteros, J. F. Gutiérrez), social (Y. Vásquez) o de actualidad (N. Cea Esteruelas).

Mucho se ha escrito sobre estos temas. Una amplia revisión bibliográfica con reseñas específicas de algunas publicaciones destacadas se presenta en el número 1 del Boletín Veritas. Revista de información bibliográfica que completa este volumen de la revista Monograma. 